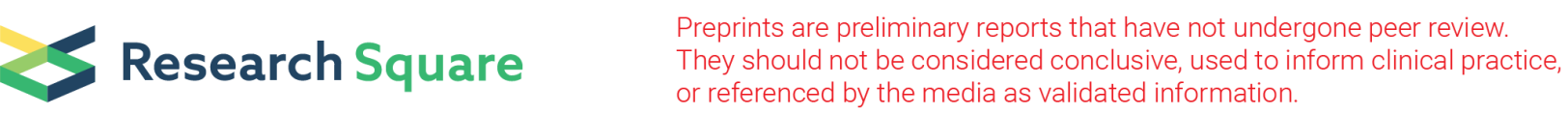

\title{
Saving Species in a Snap: On the Feasibility and Efficacy of Augmented Reality-based Wildlife Interactions for Biodiversity Conservation
}

Daniel Pimentel ( $\sim$ pimend@uoregon.edu )

University of Oregon

\section{Research Article}

Keywords: Augmented reality, depth mapping, biodiversity, environmentalism, conservation, social presence, plausibility

Posted Date: December 14th, 2021

DOI: https://doi.org/10.21203/rs.3.rs-1171413/v1

License: (c) (1) This work is licensed under a Creative Commons Attribution 4.0 International License. Read Full License

Version of Record: A version of this preprint was published at Journal for Nature Conservation on February 1st, 2022. See the published version at https://doi.org/10.1016/j.jnc.2022.126151. 


\section{Abstract}

Interactions with wildlife can contribute to biodiversity conservation outcomes, though safety and accessibility considerations limit animal encounters from being a viable strategy. This investigation explores the feasibility of mobile augmented reality to facilitate interactions with wildlife and encourage biodversity conservation. A mobile augmented reality experience (Snapchat lens), titled "Penguin Rescue!", was created to allow users to rehabilitate an oil-slicked virtual penguin. Study 1 distributed the lens globally to Snapchat users $(N=63,605)$ who spent an average of 47 seconds rehabilitating the penguin; psychographic data showed pro-environmental interests were not associated with the lens' use. Study 2 employed a within-subjects experimental design $(\mathrm{N}=80)$ to examine the effects of Penguin Rescue! on conservation outcomes. Results showed that the interaction increased connectedness with the species. Moreover, social presence and plausibility served as key mechanisms contributing to environmental concern and behavioral intentions. Overall, results clarify how biophilic interactions via augmented reality can benefit biodiversity conservation.

\section{Introduction}

Biodiversity declines and habitat losses continue to be a global cause for concern, spurring calls for interdisciplinary solutions to curtail species degradation (McElwee et al., 2020). Yet, despite heightened awareness and global strategies to address biodiversity loss (Dinerstein et al., 2020), the protection of non-human life is impeded by a myriad of macro- and micro-level factors, such as rapid urbanization (Mcdonald et al., 2008) and plastic use (Hasnat \& Rahman, 2018), respectively. At a sociological level, ecological instability is also a symptom of a larger issue: a shift in human orientation away from the natural world (biophilia) and towards digital variants (videophilia) (Edwards \& Larson, 2020). This disconnection from nature, and the plight of its species, presumably translates to a diluted understanding of, and concern for, the environment.

New media technology is one potential culprit responsible for declining environmental concern. Indeed, direct interactions with nature have steadily declined, partly because humans have less access to, and interest in, non-human beings. Paradoxically, environmental organizations and scholars have suggested that embracing emerging technologies, rather than advocating for reduced reliance, can be an effective strategy for engaging audiences with environmental issues (Berger-Tal \& Lahoz-Monfort, 2018). Thus, this investigation broadly asks: how can technology serve as a bridge, rather than a perpetual divider, between humans and threatened species?

Cross-reality (XR) media platforms, such as augmented reality (AR), are providing promising, accessible solutions for environmental organizations seeking to connect disparate audiences with threatened wildlife. Popular mobile AR applications, such as Snapchat, allow audiences to integrate virtual content into their physical space (Azuma, 1997), creating an illusory sense of "being with" (copresence) virtual characters (Kim et al., 2020). This affordance ultimately allows mobile AR users to engage in pseudo interactions with (virtual) wildlife in ways that elicit physiological and psychological responses that are 
comparable to those elicited during in vivo exposure (Zimmer et al., 2021). Indeed, organizations like the National Wildlife Federation have leveraged this to facilitate AR-based interactions with the threatened LA Mountain Lion (Puma concolor) (Cohen, 2021), for example. Similar mobile AR prototypes have also been built to connect audiences with the threatened Northern White Rhino ("The Last Three Northern White Rhinos to Be 'Digitally Resurrected' in New York Using Augmented Reality," 2017) and the endangered Golden Snub-nosed Monkey (Immersive Augmented Reality App Brings the Forest into Your Home, 2020).

Despite the growing popularity of mobile AR-based wildlife encounters, there remains little insight into the usage and efficacy of such encounters, and frameworks to guide their development and distribution.

Specifically, there is scant empirical evidence articulating (a) psychographic profiles of users, (b) whether such experiences contribute to conservation outcomes, and (c) the mechanisms through which such encounters contribute to those outcomes. Thus, we propose the following research questions to guide this investigation:

RQ1: What user demographics and psychographic are associated with AR-based wildlife experiences?

RQ2: How do AR-based wildlife interactions influence to pro-environmental outcomes?

In this paper, we detail the development, usage, and efficacy of an AR-based wildlife encounter within Snapchat, a leading social AR platform. First, we outline the development of a Snapchat Lens, "Penguin Rescue!," an interactive AR experience allowing users to rehabilitate oil-slicked Galapagos Penguins (Spheniscus mendiculus). Second, we outline an exploratory descriptive study by distributing Penguin Rescue! to global Snapchat users, assessing a range of demographic and usage information. Lastly, we discuss results from an online experiment testing Penguin Rescue's impact on pro-environmental outcomes, outlining the psychological mechanisms through which such outcomes emerge.

\section{Literature Review}

\section{The Biophilia Hypothesis}

Direct interactions with nature, such as hiking and petting animals, are known to contribute towards conservation outcomes (Kleespies et al., 2020), an effect attributed at least in part to the Biophilia Hypothesis. Proposed by Wilson (1986), the Biophilia Hypothesis posits that humans exhibit an aesthetic and emotional affinity for nature and wildlife, a phenomenon exhibited even by young children (DeLoache et al., 2011). However, scholars contend that this innate appreciation of living processes (Biophilia) is actually learned and experiential in nature (Born et al., 2001). Put differently, Biophilia is a conceptual framework that explains the emotional and psychological implications of direct experiences with nature, namely how they can build a learned appreciation for biodiversity and encourage advocacy for its preservation (Simaika \& Samways, 2010).

Despite the promise of direct wildlife encounters as a conduit to pro-environmental attitudes and behaviors, several factors inhibit the feasibility of this approach. Human advancements (e.g., 
urbanization) have estranged people from nature and wildlife, a gap which has negatively impacted biodiversity conservation efforts (Miller, 2005). As Miller notes, society must restore "human connections with the natural world by affording the possibility of meaningful interaction with nature in close proximity to the places where people live and work" (p. 433). However, factors such as cost and accessibility ultimately prevent direct wildlife interactions from serving as a scalable conservation strategy. Moreover, while threatened species are the most sought after the general public at zoos (Carr, 2016), direct interactions with these animals are impractrical due to limited numbers, safety concerns, and cost. As such, environmental organizations rely on alternative experiences, such as the use of media, to connect audiences to the plight of wildlife.

\section{Virtual Wildlife Interactions}

Traditional media-based solutions, such as nature documentaries, are limited in their ability to promote pro-environmental attitudinal or behavior change (Dunn et al., 2020). This deficiency can be attributed in part to the technological limitations of traditional media platforms, namely their (in)ability to facilitate interactive exchanges between users and the content itself. As Wilson notes, the natural world is incredibly information-rich (Wilson, 1986) and replete with sensory cues. Cues are defined as any sensory information accessible within a particular environment (Xu \& Liao, 2020), and the myriad of cues available during a wildlife encounter (e.g., mutual awareness) are absent when species are accessed through traditional media. Conversely, XR platforms, such as virtual and augmented reality (VR/AR), more easily enable interactive and engaging learning experiences with scientific (Markowitz et al., 2018) and conservation-related topics (Fauville et al., 2020). In essence, compared to traditional media, the unique affordances of XR platforms enable realistic two-way communication between users and (virtual) wildlife.

Specific to AR-based wildlife encounters, extant work has largely examined the impact of virtual animals in the context of exposure therapy (Botella et al., 2016; Kurscheidt et al., 2019; Wrzesien et al., 2015). The pro-environmental implications of AR-based wildlife encounters are vastly understudied, though extant literature suggests that such experiences should contribute to specific pro-environmental outcomes akin to those elicited after in vivo exposure (Kleespies et al., 2020). That is, much like direct experiences with wildlife cultivate connectedness with the species (Balmford et al., 2002), which is associated with proenvironmental attitudes and behavioral intentions (Davis et al., 2009; Pimentel, 2021; Pimentel et al., 2018), so too may interactions with virtual wildlife. Indeed, the equivalence of AR-based interactions is believed to be rooted in the platform's capacity for eliciting two orthogonal phenomena: presence and plausibility illusion (Psi). Both variables ultimately contribute towards realistic responses to virtual scenarios in VR (Steptoe et al., 2013) and AR (Eckhoff et al., 2020).

\section{Spatial and Social Presence}


Presence is considered a multidimensional construct comprised of two distinct categories: spatial presence and social presence (Heeter, 2003). Spatial presence is the subjective sense of being in a virtual environment (Steuer, 1992). Social presence is defined as a sense of "being with" other beings in a shared space (Oh et al., 2018). As most AR-based interactions embed virtual content into the user's physical environment, there is a presumed baseline of spatial presence that renders its measurement redundant. However, for users interacting with virtual characters in AR, the sense of being mutually aware of the shared space is imperative. For example, previous work on AR-based interactions among people suggests that interactions are more engaging when interactants appear to share the same physical space (Toet et al., 2021). Broadly, social presence mediates user responses to virtual content (Miller \& Bailenson, 2020), contributing to affective (Jin, 2011) and behavioral responses (Yoo \& Drumwright, 2018). In the context of human-wildlife interactions, a greater sense of social presence with wildlife is thus presumed to contribute to key affective and behavioral responses towards the species.

\section{Plausibility Illusion}

Plausibility illusion (Psi) refers to the illusory sense that the virtual scenario being shown is actually occurring (Sanchez-Vives \& Slater, 2005), which helps users respond to events as if they are real. Psi is determined by a myriad of factors, including the system's capacity to present events directly tied to the user's actions, and the overall credibility of the scenario. While both presence and Psi were originally created within the context of VR, both social presence (Yoon et al., 2019) and Psi (Eckhoff et al., 2020) measures are regularly adapted to AR-based scenarios. Specific to wildlife interactions in $A R$, high Psi would indicate the user knows that they are not actually engaging with a living being, but they still feel as though they are, which elicits responses akin to if they were actually engaging in the activity (Slater \& Sanchez-Vives, 2016). Responses to plausible interactions with wildlife in AR should thus elicit pro-environmental responses akin to when those interactions occur in real life (Kleespies et al., 2020).

\section{Factors Shaping Social Presence and Psi}

Developers keen on creating AR-based wildlife experiences must account for the myriad of factors that influence social presence and Psi, considering their influence over user responses to simulated content. Factors such as a virtual characters' proximity (Pimentel et al., 2021), behavioral responsiveness (Järvelä et al., 2021), and appearance (Wang et al., 2019) all influence social presence. Additionally, the type of task (Dubosc et al., 2021) and the level of interactivity (Pimentel et al., 2021) (user control) afforded by the system can influence social presence and downstream responses to content. The character's relationship to the environment, namely its spatial and behavioral coherence, serve as cues that are integral to social presence and Psi. As previously mentioned, cues are defined as any sensory information accessible within a communication environment (Xu \& Liao, 2020), and XR platforms enable virtual wildlife to demonstrate dynamic cues that contribute to perceptual realism. For example, in AR, virtual 
content (e.g., animals, objects) can be naturally occluded by the physical environment, which in turn contributes to plausibility and social presence (Kim, Bruder, et al., 2017; Kim, Maloney, et al., 2017).

In sum, the collective affordances of XR enable mediated interactions with nature to elicit psychological and emotional effects akin to in vivo exposure. For example, research shows that biophilic interactions with physical (real-world) and virtual nature elicit similar physiological and psychological responses (Yin et al., 2019). Thus, the current investigation proposes that direct interactions with wildlife through AR can contribute to pro-environmental outcomes, and that such outcomes are contingent on the experience's capacity to sustain a sense of social presence and PSi. In line with this view, the following hypotheses are proposed:

H1: Interacting with virtual wildlife in AR will increase pro-environmental attitudes (INS and environmental concern).

H2: Social presence with virtual wildlife will significantly contribute to pro-environmental attitudes and behavioral intentions.

H3: Psi will significantly contribute to pro-environmental attitudes and behavioral intentions.

The current investigation sought to test these hypotheses by developing and distributing an AR-based wildlife encounter capable of contributing to pro-environmental outcomes. In the subsequent sections, the development of an AR-based penguin rehabilitation experience for Snapchat, titled "Penguin Rescue!", is outlined. The global distribution of the simulation is then detailed, generating user insights into organic engagement with an AR conservation experience. Lastly, a follow-up online experiment highlights the impact of the experience on conservation outcomes.

\section{Study 1: Descriptive Analysis}

Given the potential of mediated interactions with threatened wildlife, the current work sought to extend this to AR contexts for various reasons, namely the scalability and accessibility associated with mobile AR. The AR experience further focused on a particular species and environmental threat: penguins and oil spills, respectively. Petroleum remains one of the more common toxic substances released into the ocean, and its impact is especially felt by seabirds, most notably penguins. Rehabilitating and decontaminating oil-slicked penguins involves a rigorous but delicate cleaning process, one that can significantly influence the species' survivability (Sievwright et al., 2019). By facilitating this rehabilitation in AR, the scenario would allow users to engage in a plausible and meaningful interaction with the species. The lens ultimately allows users to clean and rehabilitate an oil-slicked penguin in their environment using Snapchat.

\section{Methodological Overview}


Study 1 consisted of a descriptive study examining the organic use and distribution of Penguin Rescue! within the Snapchat ecosystem, thereby providing insight into the demographic and psychographic profiles of its user base. Penguin Rescue! was officially released and made available to all Snapchat users on Earth Day (April 22, 2021). Data collection occurred over a 2-month period between April 22 and June 22, 2021. During this period, users were able to access the lens either through the search function, scrolling through the in-app lens carousel, or exploring within Snapchat's lens ecosystem. Data (e.g., demographics, engagement) was collected and accessed through Snap Inc.'s Official Lens Creators virtual dashboard.

\section{Stimuli: Developing Penguin Rescue!}

The experience was created entirely in Lens Studio (v4.1), and leveraged various templates within the game engine, including the object placement and depth occlusion templates. The latter allows for compatible cameras to get information about detected surfaces, generating 3D meshes of the user's physical environment. This then allows for the virtual penguin to be (a) placed accurately onto a designated surface, and (b) occluded behind surfaces and physical objects in the user's space, contributing to a sense that the penguin is in the shared environment. The latter feature was implemented using ARCore Depth API, which has been used in previous work exploring real-time interactions with objects that leverage spatial awareness, allowing for occlusion, shadows, and surface interaction behaviors (Du et al., 2020). The animated penguin model was purchased via Turbosquid and re-texturized to meet the file size limitations of Lens Studio (maximum size of $4 \mathrm{MB}$ for any lens). Early versions of the lens were evaluated and refined using iterative design feedback from both Snap Inc. and Google developers.

\section{Narrative Overview}

Penguin Rescue! contains voice over to assist the user with each step in the penguin rehabilitation process. The experience begins with a splash screen and narration explaining the impact of oil spills on penguins. Afterwards, the user is informed that they can help clean one such oil-slicked penguin in their sink. After receiving instructions on how to place the penguin crate in their sink (Figure 1), thereby revealing the oil-slicked creature, the user is then given instructions on how to clean the penguin. The cleaning sequence and interaction was adapted from federally-approved guidelines for cleaning oilslicked penguins (see Figure 2) (Gilliland, 2020). It should be noted that, in addition to kitchen sinks, users may also place the penguin on any surface in their physical space. After washing and scrubbing the penguin, the creature is shown free of oil, followed by a separate splash screen celebrating the rehabilitation. A final narration details how the user can contribute to further penguin conservation efforts.

\section{User Interactions}


Users clean the penguin through two primary actions: spraying and scrubbing. First, the user sprays the penguin with a water and soap mixture by tapping-and-holding the virtual hose on their screen. Doing so sprays the liquid particles which can collide with detected surfaces in the user's space. After the initial spray, which loosens the oil on the bird and reduces the opacity of the oil layer on the penguin's 3D mesh, the user is instructed to spray the penguin again. Afterwards, the user then scrubs the penguin with a sponge by tapping-and-holding on the designated area on the screen and bringing the sponge close to the penguin's body. After scrubbing the bird, the oil layer's opacity is reduced to zero, presenting a fully cleaned penguin. This then triggers a congratulatory narration as well as a visual sign confirming their successful rehabilitation.

\section{Lens Duration}

A key consideration when designing the lens was the duration of the task in relation to other experiences in the Snapchat ecosystem. The average duration of a session (lens) is generally shorter for Snapchat users (under a minute) compared to sessions on other social platforms (Keshvadi et al., 2020). Indeed, the average duration of popular Snapchat lenses range between 20 and 30 seconds (Spangler, 2017). Thus, the Penguin Rescue! lens as created to last between 30 and 40 seconds depending on the amount of depth scanning the user had to engage in for their specific environment.

\section{Sharing Prosocial Behavior}

After completing the rehabilitation of their virtual penguin, users can share their conservation activity in several ways. First, internally within Snapchat, users can either share the video playthrough on their personal stories, or they can take a screenshot of the final screen and share the clean penguin within their network. Additionally, users are also able to share the lens itself. While the latter is a data point accessible to the Lens Creator, data on inter-user messaging of lens-specific content is not.

\section{Study 1 Results}

Table 1

Demographic Information of Penguin Rescue! Users

\begin{tabular}{llll}
\hline Age Group & $\begin{array}{l}\text { Total Users } \\
(\mathrm{N}=63,605)\end{array}$ & $\begin{array}{l}\text { Female } \\
(\mathrm{N}=41,980)\end{array}$ & $\begin{array}{l}\text { Male } \\
(\mathrm{N}=21,625)\end{array}$ \\
\hline $13-17$ & $13 \%$ & $11 \%$ & $17 \%$ \\
$18-20$ & $18 \%$ & $18 \%$ & $17 \%$ \\
\hline $21-24$ & $8 \%$ & $8 \%$ & $9 \%$ \\
$25-34$ & $24 \%$ & $24 \%$ & $23 \%$ \\
\hline $35+$ & $37 \%$ & $39 \%$ & $34 \%$
\end{tabular}




\section{Demographics}

Information was collected internally from Snapchat's internal system accessible to all Snapchat creators. In total, Penguin Rescue was played by a total of 63,605 unique Snapchat users, $66 \%$ of which identified as Female. The Lens was most popular in India, where over $23 \%$ of the users lived, followed by the United States $(10.49 \%)$, and Mexico $(9.48 \%)$. Moreover, $61 \%$ of users were older adults above the age of 24 , with the largest group represented by users above the age of 34 (Table 1).

\section{Psychographics}

Snap assigns psychographic profiles, or "Lifestyle Categories", to users based on their media consumption on snapchat. There are over 100 categories based on a variety of interests, and five (5) specific categories related to pro-environmental interests: Nature Enthusiasts, Pet and Animal Lovers, Green Living Enthusiasts, Political and Advocacy, and Philanthropy. The top psychographic (Lifestyle) categories among the users were Gamers (2.8\%), Film and TV Fans (2.66\%), Shoppers (2.61\%), Sports Fans $(2.34 \%)$, and Music Fans (2.15\%). None of the remaining interests of the audience members included pro-environmental categories.

\section{Lens Usage}

Users spent an average of 47 seconds per session cleaning the virtual penguin, suggesting a high level of involvement. Indeed, the average amount of time spent on a Snapchat lens is roughly 20 seconds (Snapchat Advertising Costs, 2021). Considering the duration of the lens was under one minute, this suggests that many users were engaged with the content. However, most users did not clean multiple penguins by re-launching the lens; users averaged one rehabilitation during the 2-month period. Lastly, roughly $7 \%$ of monthly active Snapchat users engaged the lens $(N=63,605)$, with 1,076 users sharing the lens with their friends.

\section{Study 1 Discussion}

The launch and reception of Penguin Rescue! yields applied insights into consumer perceptions of environmentally focused AR content. While environmental organizations have noted the potential of AR to engage audiences (de Souza Berchez et al., 2019), conservation oriented experiences are vastly underrepresented in the consumer AR ecosystems (e.g., Snapchat), where retail and entertainment content comprise the lion's share of simulations (Parekh et al., 2020). As such, previous work has called for scholars and industry practitioners to clarify the type of consumer AR content that can gain traction and circulate among global audiences (Liao \& lliadis, 2021), especially as it relates to interactive learning 
experiences (Maccallum \& Jamieson, 2017). In demonstrating that a biodiversity conservation experience can gain organic traction among multi-generational consumers, this work builds upon previous work exploring the feasibility of mobile AR for environmental conservation (Phipps et al., 2016).

\section{User Engagement}

The data suggests that AR-based altruistic interactions with wildlife can effectively engage users in varied contexts and cultures. The average time spent playing (47 seconds) was well above the industry standard of roughly 20 seconds (Snapchat Advertising Costs, 2021). Indeed, larger projects like the Game of Thrones Lens produced an average play time of 23 seconds (Spangler, 2017). The stark increase in average play time may be attributed to the procedural nature of the cleaning task, which involved a series of actions to be performed by the user in a particular order. This approach runs counter to the majority of AR experiences, which are more open-ended to encourage self-expression and experimentation among users. However, the data suggests that the lens was low on re-playability given that users only rehabilitated one penguin during the 2-month period.

\section{AR Development Insights}

The current work also emphasizes the need to rethink current approaches to developing environmental AR content, which are largely developed as native applications for particular devices (Prandi et al., 2019). By leveraging Snapchat's Lens Studio, Penguin Rescue! was instantly compatible with a wider array of devices than if it were made specifically for iOS or Android. This approach also reconciles potential barriers to downloading new applications from unfamiliar sources (e.g., privacy, trust) (Gu et al., 2017). For example, specific to environmental mobile applications, one study by the Taronga Zoo found that only $29 \%$ of visitors downloaded their standalone application about the effects of palm oil on Sumatran tigers, and only $10 \%$ of those visitors actually used the app (Kelly \& Skibins, 2020).

\section{Psychographic and Environmental Factors: Who Uses Conservation Lenses?}

The interest in, and effectiveness of, environmental messaging is often predicated on the psychological and contextual factors unique to key audiences (Ross, 2013). For example, previous work suggests that high environmental sensitivity (or eco-involvement) is associated with accessing, sharing, and creating environemntally-related content on social media (Cervellon, 2012). In other words, high environmentalism is associated with behaviors (e.g., media consumption) tied to the protection of the environment (see Zhang \& Zhong, 2020). This suggests that environment-related lifestyle categories administered be represented among the users who tried the lens. Yet, as noted in Study 1, there were no such categories (e.g., pet lovers, advocacy) were represented in the top 10 of lifestyle profiles within the sample of 63,605 Snapchat users who tried the lens. On the one hand, this may be a platform-specific issue due to the fact 
that (a) there are limited environment-related categories, and (b) environment-related lenses are not as readily available as those related to entertainment and retail. Coupled with the popularity of the lens, this result emphasizes the need for environmental organizations to capitalize on this media channel. On the other hand, it may be that users are indeed low on environmentalism and instead motivated by other factors to seek out the lens. One such factor may be tied to the species itself, which is often a major draw at zoos due to its perceived cuteness (Carter et al., 2020).

\section{Study 2}

The development and deployment of Penguin Rescue! broadly clarified (a) the feasibility of such experiences, and (b) basic demographic profiles of users most likely to engage in conservation-related AR content organically. It then becomes a question of assessing the capacity for such interactions to influence key conservation outcomes, such as connectedness with nature and conservation intentions. To assess the impact of Penguin Rescue! on such outcomes, an online experiment was conducted to quantify the conservation implications of the experience.

\section{Methodological Overview}

An online experiment was conducted wherein participants with active Snapchat accounts were asked to use and evaluate Penguin Rescue!. Participants were recruited through Amazon Mechanical Turk (MTurk) and compensated $\$ 3$ for their participation in the study. The study's inclusion criteria identified US adults with active Snapchat accounts.

\section{Measures}

\section{Social Presence}

Social presence $(a=.681)$, or the degree to which the user felt they were sharing the space with a mutually aware being (penguin), was assessed via a 10-item Likert scale measuring participants' level of agreement with various statements about the virtual penguin (Harms \& Biocca, 2004).

\section{Plausibility Illusion (Psi)}

Psi $(\alpha=.903)$ was measured via a 6-item 7-point Likert scale assessing users' level of agreement with various statements about the plausibility of the wildlife encounter (Slater, 2009).

\section{Perceived Interactivity}


Perceived interactivity was assessed via a 4-item 7-point Likert scale ( $a=.795)$ assessing participants' level of agreement with various statements about the experience as it related to user control (Kalyanaraman \& Wojdynski, 2015).

\section{Attitudes}

Attitudes towards the lens was measured via a 13-item 7-point Likert scale ( $a=.853)$ adapted from (Kalyanaraman \& Sundar, 2006). Items assessed participants' level of agreement with various words describing the experience.

\section{Pro-environmental Attitudes}

Pro-environmental attitudes were broadly conceptualized as feelings indicative of a subjective connection and concern for nature. These two aspects of pro-environmental attitudes were assessed by connectedness (INS) and environmental concern , respectively.

\section{INS}

INS served as a repeated-measure variable (pre- and post-intervention), and was assessed via a 1-item 7point pictorial scale assessing cognitive and affective connectedness with the species (penguin) (Schultz, 2002).

\section{Environmental Concern}

Environmental concern at T1 $(\mathrm{a}=.901)$ and T2 $(\mathrm{a}=.887)$ were measured using the same 12-item 7-point Likert scale gauging user agreement with various statements about their level of concern for various aspects of nature, including wildlife (Schultz, 2001).

\section{Pro-environmental Behavioral Intentions}

Behavioral intentions ( $\alpha=.867$ ) were assessed via a 6-item 7-point Likert scale measuring the likelihood of engaging in various activities benefitting penguin conservation. Activities included "share posts on social media", "donate money", and others. 
Table 2

Demographic information of Penguin Rescue participants from the pilot study
Age
Total
Male
$(\mathrm{N}=47)$
Female
$(\mathrm{N}=32)$
Non-binary
Group
$(\mathrm{N}=80)$
$(\mathrm{N}=1)$

$3(6 \%)$

$4(8 \%)$

$8(10 \%)$

21-24

25-34

$49(61 \%)$

$29(62 \%)$

20 (25\%)

11 (24\%)

$0(0 \%)$

$3(9 \%)$

$20(63 \%)$

$35+$

9 (28\%)

\section{Procedures}

Upon accessing the survey via MTurk, participants completed an informed consent form and answered various questions pertaining to their eligibility $(\mathrm{T} 1)$. After completing the preliminary questionnaire, which also assessed baseline levels of INS and environmental concern, participants were provided instructions on how to access the Snapchat lens on their personal device, whilst being reminded to ensure adequate lighting, sufficient audio volume, and additional instructions. After accessing and completing Penguin Rescue!, participants were prompted with questions about the experience to confirm completion. Afterwards, participants completed the remaining dependent variables outlined in the previous section (T2).

\section{Participants}

87 participants met the eligibility/inclusion criteria for the study and begun the survey. Of the 87, 3 were further excluded due to failure to confirm appropriate set-ups. Of the remaining 84,4 participants were excluded due to failure to complete the attention check after using the Snapchat lens. Thus, the final sample consisted of 80 participants $\left(M_{\text {age }}=32.45 ; S D=10.16\right)$. 47 participants identified as male, 31 as female, and one participant identified as non-binary (see Table 2).

\section{Study 2 Results}

\section{Task Completion Check}

To determine whether participants sucessfully deployed and completed the experience, several questions were posed regarding the content of Lens' conclusion. Items included questions about the visual and text contents shown at the conclusion of the Lens. Participants who answered incorrectly to these items were excluded from subsequent analyses. 
Table 3

Evaluative Variables About the Lens

\begin{tabular}{lll}
\hline Variable & Mean & SD \\
\hline Social presence & 4.7 & .83 \\
Psi & 4.98 & 1.26 \\
Interactivity & 5.71 & .91 \\
Attitudes & 5.48 & .79 \\
Behavioral Intentions & 5.36 & 1.09
\end{tabular}

\section{Descriptive and Correlational Analyses}

Participants accessed the lens in a variety of settings. Most participants interacted with the virtual penguin in their kitchens (36\%), followed by their living rooms (30\%), and bedrooms $(14 \%)$. On average, participants evaluated Penguin Rescue! favorably, and reported moderate levels of social presence (see Table 3) on par with previous work examining AR-based interactions with support animals (Norouzi et al., 2019). Pearson correlation analyses (Table 4) revealed significant positive relationships between social presence, Psi, interactivity, pro-environmental attitudes (INS, environmental concern), and behavioral intentions.

\section{Table 4}

Pearson r Correlation Coefficients Across Measured Variables in Study 2

\begin{tabular}{lccccccccccc} 
& SP & PSi & Inter & Atti & INST1 & INST2 & $\Delta$ INS & ECT1 & ECT2 T2 & $\Delta$ EC & BI \\
\hline SP & 1 & - & - & - & - & - & - & - & - & - & - \\
PSi & $.731^{* *}$ & 1 & - & - & - & - & - & - & - & - & - \\
\hline Inter & $.454^{* *}$ & $.578^{* *}$ & 1 & - & - & - & - & - & - & - & - \\
\hline Atti & $.545^{* *}$ & $.684^{* *}$ & $.825^{* *}$ & 1 & - & - & - & - & - & - & - \\
\hline INST1 & $.407^{* *}$ & $.423^{* *}$ & -0.020 & 0.157 & 1 & - & - & - & - & - & - \\
\hline INST2 & $.529^{* *}$ & $.636^{* *}$ & 0.217 & $.372^{* *}$ & $.729^{* *}$ & 1 & - & - & - & - & - \\
\hline$\Delta$ INS & 0.058 & 0.165 & $.292^{* *}$ & $.226^{*}$ & $-.553^{* *}$ & 0.167 & 1 & - & - & - & - \\
\hline ECT1 & $.363^{* *}$ & $.443^{* *}$ & $.483^{* *}$ & $.575^{* *}$ & 0.062 & 0.211 & 0.167 & 1 & - & - & - \\
\hline ECT2 & $.338^{* *}$ & $.453^{* *}$ & $.603^{* *}$ & $.676^{* *}$ & 0.041 & 0.186 & 0.166 & $.897^{* *}$ & 1 & - & - \\
\hline$\Delta$ EC & -0.115 & -0.058 & 0.165 & 0.108 & -0.054 & -0.090 & -0.031 & $-.391^{* *}$ & 0.056 & 1 & - \\
\hline BI & $.639^{* *}$ & $.639^{* *}$ & $.412^{* *}$ & $.597^{* *}$ & $.313^{* *}$ & $.495^{* *}$ & 0.151 & $.532^{* *}$ & $.534^{* *}$ & -0.089 & 1
\end{tabular}


*. Correlation is significant at the 0.05 level (2-tailed). ${ }^{* *}$. Correlation is significant at the .01 level $(2$-tailed). SP $=$ Social Presence EC = Environmental Concern. Inter $=$ Interactivity. Atti $=$ Attitudes. BI $=$ Behavioral Intentions.

\section{Changes in INS and Environmental Concern}

A repeated-measures analysis of variance (rANOVA) was conducted to examine changes in proenvironmental attitudes, namely the change in INS and environmental concern pre- and post-exposure to Penguin Rescue! (see Figure 3). Regarding connectedness, INS significantly increased from T1 (M=4.6, $\mathrm{SD}=1.95)$ to $\mathrm{T} 2(\mathrm{M}=5.06, \mathrm{SD}=1.54), F(1,52)=6.48, p=.01, \mathrm{n}_{\mathrm{p}}{ }^{2}=.11$. However, participants' environmental concern did not significantly increase from $\mathrm{T} 1(\mathrm{M}=5.65, \mathrm{SD}=.93)$ ito $\mathrm{T} 2(\mathrm{M}=5.72, \mathrm{SD}=.85), F(1,79)=.2 .23, p$ $>.05, \mathrm{n}_{\mathrm{p}}{ }^{2}=.03$. Thus, $\mathrm{H} 1$ was partially supported.

\section{Regression Analyses}

To examine whether social presence and Psi significantly predicted INS, environmental concern, and proenvironmental behavioral intentions, a series of regression analyses were conducted (Table 5). Results show that social presence significantly predicted all key dependent variables: INS, environmental concern, and behavioral intentions. Thus, $\mathrm{H} 2$ was supported. Psi similarly predicted all key dependent variables. Thus, $\mathrm{H} 3$ was supported.

\section{Table 5}

Regression Analyses of Social Presence and PSi on Dependent Variables in Study 2

\begin{tabular}{lllll}
$R^{2}$ & B & SE B & $\beta$ & t-stat \\
\hline .28 & 1.04 & .189 & .529 & $5.51^{\text {*** }}$ \\
.405 & .825 & .113 & .636 & $7.28^{* * *}$
\end{tabular}

\begin{tabular}{lllll}
$R^{2}$ & B & SE B & $\beta$ & t-stat \\
\hline .115 & .347 & .109 & .338 & $3.17^{* *}$ \\
& & & & \\
.205 & .306 & .068 & .453 & $4.48^{* * *}$ \\
& & & & \\
$R^{2}$ & B & SE B & $\beta$ & t-stat \\
\hline .408 & .841 & .115 & .639 & $7.33^{* * *}$ \\
.408 & .554 & .076 & .639 & $7.34^{* * *}$
\end{tabular}

Note: $* * * \mathrm{p}<.001 .{ }^{* *} \mathrm{p}<.01 . * \mathrm{p}<.05$. 


\section{General Discussion}

This investigation first detailed the development of a mobile AR experience for Snapchat about wildlife conservation (Penguin Rescue!). After gaining insight into the distribution and use of the lens within Snapchat's global user base, a follow-up online study demonstrated the efficacy of the experience to shape conservation outcomes. By rehabilitating a virtual penguin in their physical space, users of Penguin Rescue! reported a significant increase in connectedness to the species (INS) but not environmental concern for wildlife broadly $(\mathrm{H} 1)$. However, results did identify the importance of social presence $(\mathrm{H} 2)$ and Psi $(\mathrm{H} 3)$ as key mechanisms for conservation outcomes, namely environmental connectedness, concern, and pro-environmental behavioral intentions. Collectively, the findings yield both applied and theoretical contributions to the fields of environmental communication and human-computer interaction.

\section{Potential of Social AR for Conservation}

Previous work has highlighted the importance of leveraging new media (i.e., social media) to advance nature conservation efforts (Büscher, 2016). Yet, social media and AR are seldom perceived as tandem concepts by environmental communicators despite AR functionality being native to the largest social media networks (e.g., Snapchat, Instagram). These associations, or lack thereof, have contributed to environmental communicators overlooking AR platforms like Snapchat as a viable conduit for conservation-related experiences, namely wildlife interactions. Indeed, Snapchat has increasingly emphasized the need for AR content creators to produce more socially impactful content (Perez, 2020), which was a goal of this lens. The success of Penguin Rescue!, in terms of engagement, accents the viability and efficacy of social AR-based conservation content.

\section{Alternatives to Standalone AR Applications}

The significant increase in INS after a short interaction with virtual wildlife through Snapchat also stresses the importance of alternatives to standalone mobile AR applications. Previous work has identified that organizational apprehension around investing in AR content is partially rooted in requiring users to download a single-use, standalone application (Cranmer et al., 2016). Building Penguin Rescue! within Lens Studio ensured that download apprehension would be a non-factor, as the experience would be automatically available to millions of Snapchat users. The current work demonstrates how short interactions with wildlife can fit within the file size limitations of mobile AR. For more elaborate content, another viable alternative to standalone AR applications involves the use of WebAR, which offers ease-ofaccess by removing the burden of downloading any application, a factor determining mobile app adoption (Kumari, 2020). 


\section{Verisimilitude Between Virtual and Real-world Wildlife Interactions}

A major draw of AR is its capacity for equivalence; psychological and behavioral responses towards virtual characters in AR mimic those exhibited during real-life interactions (Miller et al., 2019). This affordance has largely resulted in the use of AR-based animal encounters for the purposes of exposure therapy, where users can passively acclimate to feared stimuli (Zimmer et al., 2021). However, the current work highlights an alternative use of this equivalence, one which demonstrates how altruistic interactions with virtual wildlife in AR can elicit pro-environmental responses common to in vivo interactions. Much like direct interactions with zoo animals can increase connectedness with the species (INS) (Kleespies et al., 2020), this investigation shows that AR-based interactions with virtual animals (penguins) also foster species connectedness, and concern for nature as a whole.

The type of interaction facilitated by the simulation is also of particular importance. In stark contrast to exposure therapy-based wildlife encounters, which are passive, user actions in Penguin Rescue! directly benefitted the well-being of the animal. Scholars note that "altruism begets altruism" in the context of monetary donations (Heger et al., 2021) and assistance for medical patients (Moshiri \& Moshiri, 2021). In other words, helping others in need can contribute towards downstream psychological changes which encourage downstream altruistic attitudes and behaviors. The current work suggests that helping virtual non-human victims also spurs altruistic motivations to protect the species, as indicated by the fact that both perceived interactivity and social presence predicted conservation behavioral intentions.

Collectively, the pro-environmental outcomes spurred by the experience lend further credence to the verisimilitude of AR-based wildlife interactions.

\section{The Role of Social Presence, Psi, and Interactivity}

Of particular importance to this investigation is the identification of psychological mechanism(s) responsible for pro-environmental responses to the AR experience. In AR- and VR-based interactions with virtual objects and characters, "presence tends to mediate responses to virtual stimuli" (Miller \& Bailenson, 2020). A strong sense of presence with virtual stimuli is known to contribute to outcomes such as enjoyment (Jin, 2011), behavioral intentions (Yoo \& Drumwright, 2018), and interest in science (Pimentel \& Kalyanaraman, 2021). Specific to altruistic outcomes, previous work has also identified social presence with virtual victims as a key predictor of empathic responses (Bouchard et al., 2013). Results from Study 2 extend the augmenting effects of social presence (and Psi) to altruistic responses towards non-human victims. Specifically, regression analyses demonstrated both social presence and Psi's role in predicting INS, environmental concern, and behavioral intentions to help threatened wildlife (penguins).

It should be noted that the positive effects of social presence and Psi are presumed to be conditional based on characteristics of the species. As alluded to in the Study 1 discussion, the popularity of Penguin 
Rescue! may be driven by the desirability of the species, as penguins exhibit many desirable traits, such as cuteness (Chiew et al., 2021). Visual characteristics of the species (e.g., cuteness) should be taken into account when interpreting the results of Study 2 considering previous work on empathic responses to the suffering of others. For example, perceiving others in pain can trigger negative outcomes when the target is threatening, but positive outcomes when the target exhibits likeable traits (Yamada \& Decety, 2009). Indeed, previous work exploring the role of animal cuteness on conservation-related responses suggest that perceived cuteness of a threatened animal may influence the relationship between social presence and pro-environmental behaviors (Pimentel et al., 2018). In other words, the subjective sense of "being with" a threatened animal may only contribute to conservation outcomes if the species exhibits desirable traits. Thus, future work may seek to explore how perceived cuteness may moderate the relationship between social presence (and Psi) and key conservation outcomes.

\section{How Does Social Presence Influence Conservation?}

While not direclty measured in this investigation, it is important to acknowledge the potential role of animal-oriented empathy and its relationship to social presence. Previous work has shown that social presence can indirectly encourage prosocial behavior by increasing empathic responses towards human victims (Pimentel et al., 2021). Empathy towards wildlife was not directly measured, and thus social presence may indeed be influencing change in INS and environmental concern through empathy-related responses, such as empathic joy. Empathic joy is characterized by a pleasurable feeling stemming from seeing a person in need experience relief (Batson et al., 2008). In this way, rehabilitating an oil-slicked penguin may have contributed to empathic joy, a known correlate with victim-oriented concern (Smith et al., 1989). However, it should be noted that human- and animal-oriented empathy are two distinct constructs (Paul, 2000), the latter of which is overlooked in research examining the empathic implications of immersive storytelling in AR/VR (Foxman et al., 2021). Future research may seek to elucidate the relationship between social presence and pro-environmental attitudes (e.g., concern, INS) by examining animal-oriented empathic joy as a potential mediator.

\section{Interactivity: Beyond Mere Wildlife Exposure}

The sense of being with virtual wildlife notwithstanding, the interplay between user actions and wildlife responses, or interactivity, was also found to be integral to cultivating pro-environmental outcomes. The perceived interactivity of an AR application directly contributes to attitudes and behavioral intentions in various contexts, including AR-based job training (Papakostas et al., 2021) and retail applications (Park \& Yoo, 2020). Results from Study 2 extend this work by elucidating perceived interactivity's role in augmented the impact of environmental content. As previously noted, correlational analyses found positive associations between interactivity, environmental concern, and behavioral intentions (see Table 4). While it may seem intuitive to afford users greater interactivity within an AR experience, extant environmental simulations remain limited in their implementation of interactivity. For example, Tell a Tail 
Comic AR allows users to scan pages of a comic book about animal welfare and observe animated AR storytelling content (Bala et al., 2020), though users are unable to directly influence virtual characters. Similar conservation AR apps also fail to facilitate direct interactions with wildlife (Pombo \& Marques, 2019). Even proponents of using AR for connecting audiences to nature overlook the ability for such technologies to facilitate human-wildlife interactions (Stinson, 2017). The results from this study encourage developers to think beyond mere exposure to wildlife, and consider more direct interactions with wildlife to cultivate pro-environmetnal responses.

\section{Environmental Anxiety}

Anxiety related to the prevalence of environmental threats is increasingly common among young adults (Hickman et al., 2021). Previous work suggests that audiences can respond to such emotions by engaging in various behaviors, namely problem-focused coping. That is, users can engage in individual actions that re-frame the problem as amenable to remedying, and are rooted in positive changes to affected parties (Clayton, 2020). In this way, helping virtual wildlife may assist in problem-focused coping. However, as shown in Table 1, the majority of users who sought out Penguin Rescue! were older adults, which are less susceptible to anxiety related to environmental issues (Clayton, 2020). A logical question stemmed from this insight relates to how AR-based wildlife experiences can, and should, be framed to engage younger audiences with the environmental issues agitating their concerns.

\section{Limitations And Future Work}

\section{Generalizability \& Platform-specific Factors}

There are several limitations to acknowledge when interpreting the results from both studies. Specific to Study 1, Snap's dashboard limited the researcher's ability to connect users who engaged the lens and their specific search terms and psychographic profiles. Moreover, the inability to quantify the categorization of users inhibits our ability to definitively articulate how trait environmentalism influenced motivations to download and use Penguin Rescue!

Specific to Study 2, conservation implications associated with the AR experience are generalizable to audiences that fit within Snapchat's demographic. Snapchat's user base skews younger compared to other platforms (Grieve, 2017), an important distinction considering how age influences responses to virtual interactions (Siriaraya \& Siang Ang, 2012). Moreover, while behavioral intentions remain a prominent outcome measure in experimental research, extrapolating conservation intentions to actual conservation behaviors should be approached with caution. For example, previous VR research has shown that conservation intentions measured after exposure to threatened wildlife did not predict actual conservation behaviors in a sample of US teens (Pimentel et al., 2018).

\section{Controlling for Coherence}


Due to the COVID-19 pandemic Study 2's experiment was conducted remotely, raising slight concerns regarding the plausibility of the encounter, specifically establishing and maintaining Psi throughout the interaction. Plausibility is bound to the (in)coherence, or the (in)appropriateness, of interaction elements within a mediated experience (Skarbez et al., 2018). Given the remote experiment, we were limited in our ability to ensure participants' interaction with the penguin occurred in a plausible location (e.g., sink, bathtub). On the one hand, the limited control over coherence mismatches (e.g., cleaning a penguin on one's desk) may have detracted from plausibility. On the other hand, allowing users to decide where to place the penguin is representative of how AR users engage in spatial experiences. Moreover, placement of the penguin on other surfaces would not have impeded on key features such as occlusion and particle collisions, which are surface agnostic. It is also important to acknowledge the possibility that participants were interrupted via text notifications on their device or co-inhabitants during the experience. Considering that interruptions during mobile sessions can contribute to frustration and disinterest (Ramtohul \& Khedo, 2021), replicating this study in a naturalistic setting with researcher supervision would reduce such interruptions.

Lastly, this investigation highlights potential adverse implications associated with engaging in humanwildlife interactions in AR. Previous work has shown that (real-world) direct interactions with wildlife, such as hairy-nosed wombats (Lasiorhinus latifrons), can lead to improved human-animal interactions. That is, as animals interact with humans they can become less reactive and easily handled due to habituation (Hogan et al., 2011). A potential issue may arise when the illusion of direct interaction with species in AR lead to expectations of habituation and docility from animals during real-world encounters. However, it is our hope that this outcome inspires more developers and organizations to leverage mobile AR platforms to facilitate similar, but altogether unique, interactions with threatened wildlife. Infusing proenvironmental content into the growing AR ecosystem may contribute to its growing ubiquity and simultaneously cultivate a more environmentally conscious community.

\section{Considerations for AR-based Wildlife Encounters}

The benefits of using AR games for conservation come with equally important caveats. In the context of human-wildlife interactions, AR encounters may yield unwanted consequences, such as encouraging exploitation of wildlife (Dorward et al., 2017). Another factor relates to species representation in these experiences. Content creators must avoid falling into similar patterns as Zoos as it relates what species are featured. Previous work has shown that children know more about, and care for, exotic species versus local species (Ballouard et al., 2011; Sommer, 2008). Indeed, this is a major reason why zoo marketing efforts revolve around showcasing large, uncommon, and charismatic species (e.g., elephants, lions, penguins) (Carr, 2016). The benefits of AR-based interactions with wildlife should extend to most species, barring phobias, and thus local biodiversity should be considered when designing conservation-related AR content.

\section{Conclusion}


The media equation paradigm posits that media users respond to mediated content as if it is occurring in real life (Reeves \& Nass, 1998). The current investigation extends this work within the context of environmental communication: mobile AR users are affected by virtual encounters with wildlife in ways that are similar to in-vivo exposure. Moreover, the extend of these effects are determined at least in part by (a) the degree to which users feel they are sharing the space with the creature, and (b) the plausibility of the interaction. Broadly, this work clarifies the mechanisms through which mobile AR-based wildlife encounters can help achieve large-scale pro-environmental outcomes, and hopefully spurs further investigations into mediated wildlife interactions as a strategy for biodiversity conservation.

\section{Declarations}

Acknowledgments

This research was made possible by the assistance provided through the [Anonymized Project Name] by [Anonymized Company Names].

Conflict of Interest Statement

The authors declare that they have no known competing financial interests or personal relationships that could have appeared to influence the work reported in this paper.

\section{References}

1. Azuma, R. T. (1997). A Survey of Augmented Reality. Presence: Teleoperators and Virtual Environments, 6(4), 355-385. https://doi.org/10.1162/pres.1997.6.4.355

2. Bala, P., Dionisio, M., Oliveira, S., Andrade, T., \& Nisi, V. (2020). Tell a Tail: Leveraging XR for a Transmedia on Animal Welfare (pp. 223-239). https://doi.org/10.1007/978-3-030-65736-9_19

3. Ballouard, J.-M., Brischoux, F., \& Bonnet, X. (2011). Children Prioritize Virtual Exotic Biodiversity over Local Biodiversity. PLoS ONE, 6(8), e23152. https://doi.org/10.1371/journal.pone.0023152

4. Balmford, A., Clegg, L., Coulson, T., \& Taylor, J. (2002, September). Why Conservationists Should Heed Pokémon. Science. https://www.bioteach.ubc.ca/TeachingResources/GeneralScience/PokemonWildlife.pdf

5. Batson, C. C., Ahmad, N., Powell, A. A., Stocks, S. J., \& Gardner, W. L. (2008). Prosocial motivation (J. Y. Shah \& W. L. Gardner (Eds.)). Guilford Publications.

6. Berger-Tal, O., \& Lahoz-Monfort, J. J. (2018). Conservation technology: The next generation. Conservation Letters, 11(6), e12458. https://doi.org/10.1111/conl.12458

7. Born, R. J. G. van den, Lenders, R. H. J., Groot, W. T. de, \& Huijsman, E. (2001). The new biophilia: an exploration of visions of nature in Western countries. Environmental Conservation, 28(1), 65-75. https://doi.org/10.1017/S0376892901000066 
8. Botella, C., Pérez-Ara, M. Á., Bretón-López, J., Quero, S., García-Palacios, A., \& Baños, R. M. (2016). In Vivo versus Augmented Reality Exposure in the Treatment of Small Animal Phobia: A Randomized Controlled Trial. PLOS ONE, 11(2), e0148237. https://doi.org/10.1371/journal.pone.0148237

9. Bouchard, S., Bernier, F., Boivin, É., Dumoulin, S., Laforest, M., Guitard, T., Robillard, G., Monthuy-Blanc, J., \& Renaud, P. (2013). Empathy Toward Virtual Humans Depicting a Known or Unknown Person Expressing Pain. Cyberpsychology, Behavior, and Social Networking, 16(1), 61-71. https://doi.org/10.1089/cyber.2012.1571

10. Büscher, B. (2016). Nature 2.0: Exploring and theorizing the links between new media and nature conservation. New Media \& Society, 18(5), 726-743. https://doi.org/10.1177/1461444814545841

11. Carr, N. (2016). Ideal animals and animal traits for zoos: General public perspectives. Tourism Management, 57, 37-44. https://doi.org/10.1016/j.tourman.2016.05.013

12. Carter, M., Webber, S., Rawson, S., Smith, W., Purdham, J., \& McLeod, E. M. (2020). Virtual Reality in the Zoo: A Qualitative Evaluation of a Stereoscopic Virtual Reality Video Encounter with Little Penguins (Eudyptula minor). Journal of Zoo and Aquarium Research, 8(2016), 239-245.

13. Cervellon, M.-C. (2012). Victoria's Dirty Secrets. Journal of Advertising, 41(4), 133-145. https://doi.org/10.1080/00913367.2012.10672462

14. Chiew, S. J., Hemsworth, P. H., Melfi, V., Sherwen, S. L., Burns, A., \& Coleman, G. J. (2021). Visitor Attitudes Toward Little Penguins (Eudyptula minor) at Two Australian Zoos. Frontiers in Psychology, 12. https://doi.org/10.3389/fpsyg.2021.626185

15. Clayton, S. (2020). Climate anxiety: Psychological responses to climate change. Journal of Anxiety Disorders, 74, 102263. https://doi.org/10.1016/j.janxdis.2020.102263

16. Cohen, D. (2021, April 27). Verizon, Snapchat Join Forces on Another 5G-Enabled AR Landmarker Lens. Adweek. https://www.adweek.com/social-marketing/verizon-snapchat-join-forces-on-another5g-enabled-ar-landmarker-lens/

17. Cranmer, E., Jung, T., tom Dieck, M. C., \& Miller, A. (2016). Understanding the Acceptance of Augmented Reality at an Organisational Level: The Case of Geevor Tin Mine Museum. In Information and Communication Technologies in Tourism 2016 (pp. 637-650). Springer International Publishing. https://doi.org/10.1007/978-3-319-28231-2_46

18. Davis, J. L., Green, J. D., \& Reed, A. (2009). Interdependence with the environment: Commitment, interconnectedness, and environmental behavior. Journal of Environmental Psychology, 29(2), 173180. https://doi.org/10.1016/j.jenvp.2008.11.001

19. de Souza Berchez, F. A., Ghilardi-Lopes, N. P., Raimundo, S. G., \& Saraiva, A. M. (2019). Integrating Emerging Pedagogies and Technologies in Environmental and Formal Basic Education (pp. 53-67). https://doi.org/10.1007/978-3-030-05138-9_4

20. De Witte, N. A. J., Scheveneels, S., Sels, R., Debard, G., Hermans, D., \& Van Daele, T. (2020). Augmenting Exposure Therapy: Mobile Augmented Reality for Specific Phobia. Frontiers in Virtual Reality, 1. https://doi.org/10.3389/frvir.2020.00008 
21. DeLoache, J. S., Pickard, M. B., \& LoBue, V. (2011). How very young children think about animals. In How animals affect us: Examining the influences of human-animal interaction on child development and human health. (pp. 85-99). American Psychological Association. https://doi.org/10.1037/12301-004

22. Dinerstein, E., Joshi, A. R., Vynne, C., Lee, A. T. L., Pharand-Deschênes, F., França, M., Fernando, S., Birch, T., Burkart, K., Asner, G. P., \& Olson, D. (2020). A “Global Safety Net” to reverse biodiversity loss and stabilize Earth's climate. Science Advances, 6(36), eabb2824. https://doi.org/10.1126/sciadv.abb2824

23. Dorward, L. J., Mittermeier, J. C., Sandbrook, C., \& Spooner, F. (2017). Pokémon Go: Benefits, Costs, and Lessons for the Conservation Movement. Conservation Letters, 10(1), 160-165. https://doi.org/10.1111/conl.12326

24. Du, R., Turner, E., Dzitsiuk, M., Prasso, L., Duarte, I., Dourgarian, J., Afonso, J., Pascoal, J., Gladstone, J., Cruces, N., Izadi, S., Kowdle, A., Tsotsos, K., \& Kim, D. (2020). DepthLab: Real-time 3D interaction with depth maps for mobile augmented reality. UIST 2020 - Proceedings of the 33rd Annual ACM Symposium on User Interface Software and Technology, 829-843. https://doi.org/10.1145/3379337.3415881

25. Dubosc, C., Gorisse, G., Christmann, O., Fleury, S., Poinsot, K., \& Richir, S. (2021). Impact of Avatar Anthropomorphism and Task Type on Social Presence in Immersive Collaborative Virtual Environments. 2021 IEEE Conference on Virtual Reality and 3D User Interfaces Abstracts and Workshops (VRW), 438-439. https://doi.org/10.1109/VRW52623.2021.00101

26. Dunn, M. E., Mills, M., \& Veríssimo, D. (2020). Evaluating the impact of the documentary series Blue Planet II on viewers' plastic consumption behaviors. Conservation Science and Practice, 2(10). https://doi.org/10.1111/csp2.280

27. Eckhoff, D., Cassinelli, A., Liu, T., \& Sandor, C. (2020). Psychophysical Effects of Experiencing Burning Hands in Augmented Reality (pp. 83-95). https://doi.org/10.1007/978-3-030-62655-6_5

28. Edwards, R. C., \& Larson, B. M. H. (2020). When screens replace backyards: strategies to connect digital-media-oriented young people to nature. Environmental Education Research, 26(7), 950-968. https://doi.org/10.1080/13504622.2020.1776844

29. Fauville, G., Queiroz, A. C. M., \& Bailenson, J. N. (2020). Virtual reality as a promising tool to promote climate change awareness. In Technology and Health (pp. 91-108). Elsevier. https://doi.org/10.1016/B978-0-12-816958-2.00005-8

30. Foxman, M., Markowitz, D. M., \& Davis, D. Z. (2021). Defining empathy: Interconnected discourses of virtual reality's prosocial impact. New Media \& Society, 23(8), 2167-2188. https://doi.org/10.1177/1461444821993120

31. Gilliland, H. C. (2020, April). 'Every bird matters': The science behind oiled seabird rehabilitation. National Geographic. https://www.nationalgeographic.com/animals/article/oil-spill-birdrehabilitation-advances 
32. Grieve, R. (2017). Unpacking the characteristics of Snapchat users: A preliminary investigation and an agenda for future research. Computers in Human Behavior, 74, 130-138.

https://doi.org/10.1016/j.chb.2017.04.032

33. Gu, J., Xu, Y. (Calvin), Xu, H., Zhang, C., \& Ling, H. (2017). Privacy concerns for mobile app download: An elaboration likelihood model perspective. Decision Support Systems, 94, 19-28. https://doi.org/10.1016/j.dss.2016.10.002

34. Harms, C., \& Biocca, F. (2004). Internal Consistency and Reliability of the Networked Minds Measure of Social Presence. Seventh Annual International Workshop: Presence 2004.

35. Hasnat, M. A., \& Rahman, M. A. (2018). A review paper on the hazardous effect of plastic debris on marine biodiversity with some possible remedies. Asian Journal of Medical and Biological Research, 4(3), 233-241. https://doi.org/10.3329/ajmbr.v4i3.38461

36. Heeter, C. (2003). Reflections on Real Presence by a Virtual Person. Presence: Teleoperators and Virtual Environments, 12(4), 335-345. https://doi.org/10.1162/105474603322391587

37. Heger, S. A., Slonim, R., Tausch, F., \& Tymula, A. (2021). Altruism among consumers as donors. Journal of Economic Behavior \& Organization, 189, 611-622.

https://doi.org/10.1016/j.jebo.2021.06.024

38. Hickman, C., Marks, E., Pihkala, P., Clayton, S., Lewandowski, E. R., Mayall, E. E., Wray, B., Mellor, C., \& van Susteren, L. (2021). Young People's Voices on Climate Anxiety, Government Betrayal and Moral Injury: A Global Phenomenon. SSRN Electronic Journal. https://doi.org/10.2139/ssrn.3918955

39. Hogan, L. A., Johnston, S. D., Lisle, A. T., Keeley, T., Wong, P., Nicolson, V., Horsup, A. B., Janssen, T., \& Phillips, C. J. C. (2011). Behavioural and physiological responses of captive wombats (Lasiorhinus latifrons) to regular handling by humans. Applied Animal Behaviour Science, 134(3-4), 217-228. https://doi.org/10.1016/j.applanim.2011.07.010

40. Immersive augmented reality app brings the forest into your home. (2020). World Wildlife FundWorld Wildlife Fund. https://www.worldwildlife.org/pages/wwf-forests

41. Järvelä, S., Cowley, B., Salminen, M., Jacucci, G., Hamari, J., \& Ravaja, N. (2021). Augmented Virtual Reality Meditation. ACM Transactions on Social Computing, 4(2), 1-19. https://doi.org/10.1145/3449358

42. Jin, S.-A. A. (2011). "It Feels Right. Therefore, I Feel Present and Enjoy": The Effects of Regulatory Fit and the Mediating Roles of Social Presence and Self-Presence in Avatar-Based 3D Virtual Environments. Presence: Teleoperators and Virtual Environments, 20(2), 105-116. https://doi.org/10.1162/pres_a_00038

43. Kalyanaraman, S., \& Sundar, S. S. (2006). The Psychological Appeal of Personalized Content in Web Portals: Does Customization Affect Attitudes and Behavior? Journal of Communication, 56(1), 110132. https://doi.org/10.1111/j.1460-2466.2006.00006.x

44. Kalyanaraman, S., \& Wojdynski, B. W. (2015). Affording control: How customization, interactivity, and navigability affect psychological responses to technology. The Handbook of the Psychology of Communication Technology. 
45. Kelly, A., \& Skibins, J. C. (2020). Inspiring Wildlife Conservation Behaviors through Innovations in Zoo Exhibit Design. Visitor Studies, 1-21. https://doi.org/10.1080/10645578.2020.1824881

46. Keshvadi, S., Karamollahi, M., \& Williamson, C. (2020). Traffic Characterization of Instant Messaging Apps: A Campus-Level View. 2020 IEEE 45th Conference on Local Computer Networks (LCN), 225232. https://doi.org/10.1109/LCN48667.2020.9314799

47. Kim, H., Kim, T., Lee, M., Kim, G. J., \& Hwang, J.-I. (2020). Don't Bother Me: How to Handle ContentIrrelevant Objects in Handheld Augmented Reality. 26th ACM Symposium on Virtual Reality Software and Technology, 1-5. https://doi.org/10.1145/3385956.3418948

48. Kim, K., Bruder, G., \& Welch, G. (2017). Exploring the effects of observed physicality conflicts on realvirtual human interaction in augmented reality. Proceedings of the 23rd ACM Symposium on Virtual Reality Software and Technology, 1-7. https://doi.org/10.1145/3139131.3139151

49. Kim, K., Maloney, D., Bruder, G., Bailenson, J. N., \& Welch, G. F. (2017). The effects of virtual human's spatial and behavioral coherence with physical objects on social presence in AR. Computer Animation and Virtual Worlds, 28(3-4), e1771. https://doi.org/10.1002/cav.1771

50. Kleespies, M. W., Gübert, J., Popp, A., Hartmann, N., Dietz, C., Spengler, T., Becker, M., \& Dierkes, P. W. (2020). Connecting High School Students With Nature - How Different Guided Tours in the Zoo Influence the Success of Extracurricular Educational Programs. Frontiers in Psychology, 11. https://doi.org/10.3389/fpsyg.2020.01804

51. Kumari, T. (2020). Review of Effective Implementation of Augmented Reality using Internet WebAR. International Journal for Research in Applied Science and Engineering Technology, 8(8), 303-307. https://doi.org/10.22214/ijraset.2020.30864

52. Kurscheidt, M., Ostapchuck, V., Sottek, F., Rauh, S. F., \& Meixner, G. (2019). Augmented Reality Exposure Therapy with Tactile Feedback for Small Animal Phobia: Hardware Concept and User Study Design. 2019 IEEE International Conference on Healthcare Informatics (ICHI), 1-7. https://doi.org/10.1109/ICHI.2019.8904800

53. Liao, T., \& lliadis, A. (2021). A future so close: Mapping 10 years of promises and futures across the augmented reality development cycle. New Media \& Society, 23(2), 258-283. https://doi.org/10.1177/1461444820924623

54. Maccallum, K., \& Jamieson, J. (2017). Exploring Augmented Reality in Education Viewed Through the Affordance Lens. 8th Annual Conference of Computing and Information Technology Education and Research in New Zealand., November. https://www.researchgate.net/publication/321024850

55. Markowitz, D. M., Laha, R., Perone, B. P., Pea, R. D., \& Bailenson, J. N. (2018). Immersive Virtual Reality Field Trips Facilitate Learning About Climate Change. Frontiers in Psychology, 9. https://doi.org/10.3389/fpsyg.2018.02364

56. Mcdonald, R. I., Kareiva, P., \& Forman, R. T. T. (2008). The implications of current and future urbanization for global protected areas and biodiversity conservation. Biological Conservation, 141(6), 1695-1703. https://doi.org/10.1016/j.biocon.2008.04.025 
57. McElwee, P., Turnout, E., Chiroleu-Assouline, M., Clapp, J., Isenhour, C., Jackson, T., Kelemen, E., Miller, D. C., Rusch, G., Spangenberg, J. H., Waldron, A., Baumgartner, R. J., Bleys, B., Howard, M. W., Mungatana, E., Ngo, H., Ring, I., \& Santos, R. (2020). Ensuring a Post-COVID Economic Agenda Tackles Global Biodiversity Loss. One Earth, 3(4), 448-461.

https://doi.org/10.1016/j.oneear.2020.09.011

58. Miller, J. R. (2005). Biodiversity conservation and the extinction of experience. Trends in Ecology \& Evolution, 20(8), 430-434. https://doi.org/10.1016/j.tree.2005.05.013

59. Miller, M. R., \& Bailenson, J. N. (2020). Augmented Reality. In The Handbook of Listening (pp. 409417). Wiley. https://doi.org/10.1002/9781119554189.ch28

60. Miller, M. R., Jun, H., Herrera, F., Yu Villa, J., Welch, G., \& Bailenson, J. N. (2019). Social interaction in augmented reality. PLOS ONE, 14(5), e0216290. https://doi.org/10.1371/journal.pone.0216290

61. Moshiri, A., \& Moshiri, A. S. (2021). Involving Patients in Their Own Health Care Choices-Altruism Begets Altruism. JAMA Network Open, 4(2), e210152.

https://doi.org/10.1001/jamanetworkopen.2021.0152

62. Norouzi, N., Kim, K., Lee, M., Schubert, R., Erickson, A., Bailenson, J., Bruder, G., \& Welch, G. (2019). Walking Your Virtual Dog: Analysis of Awareness and Proxemics with Simulated Support Animals in Augmented Reality. 2019 IEEE International Symposium on Mixed and Augmented Reality (ISMAR), 157-168. https://doi.org/10.1109/ISMAR.2019.000-8

63. Oh, C. S., Bailenson, J. N., \& Welch, G. F. (2018). A Systematic Review of Social Presence: Definition, Antecedents, and Implications. Frontiers in Robotics and Al, 5. https://doi.org/10.3389/frobt.2018.00114

64. Papakostas, C., Troussas, C., Krouska, A., \& Sgouropoulou, C. (2021). Measuring User Experience, Usability and Interactivity of a Personalized Mobile Augmented Reality Training System. Sensors, 21(11), 3888. https://doi.org/10.3390/s21113888

65. Parekh, P., Patel, S., Patel, N., \& Shah, M. (2020). Systematic review and meta-analysis of augmented reality in medicine, retail, and games. Visual Computing for Industry, Biomedicine, and Art, 3(1), 21. https://doi.org/10.1186/s42492-020-00057-7

66. Park, M., \& Yoo, J. (2020). Effects of perceived interactivity of augmented reality on consumer responses: A mental imagery perspective. Journal of Retailing and Consumer Services, 52, 101912. https://doi.org/10.1016/j.jretconser.2019.101912

67. Paul, E. S. (2000). Empathy with Animals and with Humans: Are They Linked? Anthrozoös, 13(4), 194-202. https://doi.org/10.2752/089279300786999699

68. Penguin Rescue and Rehabilitation Assistant. (2021). Khaya Volunteer Projects.

https://www.volunteerworld.com/en/volunteer-program/penguin-rescue-and-rehabilitation-assistantin-south-africa-port-elizabeth

69. Perez, S. (2020, December 8). Snap announces $\$ 3.5 \mathrm{M}$ fund directed toward AR Lens creation. Tech Crunch. https://techcrunch.com/2020/12/08/snap-announces-3-5m-fund-directed-toward-ar-lenscreation/ 
70. Phipps, L., Alvarez, V., de Freitas, S., Wong, K., Baker, M., \& Pettit, J. (2016). Conserv-AR: A Virtual and Augmented Reality Mobile Game to Enhance Students' Awareness of Wildlife Conservation in Western Australia. 15th World Conference on Mobile and Contextual Learning (MLearn), 214-225.

71. Pimentel, D. (2021). The Peril and Potential of XR-based Interactions with Wildlife. Extended Abstracts of the 2021 CHI Conference on Human Factors in Computing Systems, 1-9. https://doi.org/10.1145/3411763.3450378

72. Pimentel, D., \& Kalyanaraman, S. (2021). Virtual climate scientist: A VR learning experience about paleoclimatology for underrepresented students. Interactive Learning Environments, 1-14. https://doi.org/10.1080/10494820.2021.1969582

73. Pimentel, D., Kalyanaraman, S., \& Halan, S. (2018). Bigger is Better: A VR Penguin Rehabilitation Simulation to Study Animal Conservation Behaviors. 2018 IEEE Games, Entertainment, Media Conference (GEM), 1-9. https://doi.org/10.1109/GEM.2018.8516548

74. Pimentel, D., Kalyanaraman, S., Lee, Y.-H., \& Halan, S. (2021). Voices of the unsung: The role of social presence and interactivity in building empathy in 360 video. New Media \& Society, 1-25. https://doi.org/10.1177/1461444821993124

75. Pombo, L., \& Marques, M. M. (2019). An App that Changes Mentalities about Mobile Learning-The EduPARK Augmented Reality Activity. Computers, 8(2), 37. https://doi.org/10.3390/computers8020037

76. Prandi, C., Ceccarini, C., \& Salomoni, P. (2019). Augmenting Good Behaviour. Proceedings of the 5th EAl International Conference on Smart Objects and Technologies for Social Good, 189-194. https://doi.org/10.1145/3342428.3342688

77. Ramírez-Fernández, C., Morán, A. L., \& Meza-Kubo, V. (2018). Towards a Taxonomy of Feedback Factors Affecting the User Experience of Augmented Reality Exposure Therapy Systems for SmallAnimal Phobias. Proceedings, 2(19), 1252. https://doi.org/10.3390/proceedings2191252

78. Ramtohul, A., \& Khedo, K. K. (2021). User Experience and Engagement in Augmented Reality Systems for the Cultural Heritage Domain (pp. 227-256). https://doi.org/10.1007/978-3-030-70198-7_13

79. Reeves, B., \& Nass, C. (1998). The media equation. The Media Equation: How People Treat Computers, Television, and New Media Like Real People and Places.

80. Ross, D. G. (2013). Deep audience analysis: A proposed method for analyzing audiences for environment-related communication. Technical Communication, 60(2), 94-117.

81. Sanchez-Vives, M. V., \& Slater, M. (2005). From presence to consciousness through virtual reality. Nature Reviews Neuroscience, 6(4), 332-339. https://doi.org/10.1038/nrn1651

82. Schultz, P. W. (2001). THE STRUCTURE OF ENVIRONMENTAL CONCERN: CONCERN FOR SELF, OTHER PEOPLE, AND THE BIOSPHERE. Journal of Environmental Psychology, 21(4), 327-339. https://doi.org/10.1006/jevp.2001.0227

83. Schultz, P. W. (2002). Inclusion with Nature: The Psychology Of Human-Nature Relations. In Psychology of Sustainable Development (pp. 61-78). Springer US. https://doi.org/10.1007/978-14615-0995-0_4 
84. Sievwright, K. A., Battley, P. F., McConnell, H., Armstrong, D. P., \& Morgan, K. J. (2019). Survival rates of oil-rehabilitated and non-rehabilitated little penguins after the C/V Rena oil spill, New Zealand. Marine Pollution Bulletin, 146, 317-325. https://doi.org/10.1016/j.marpolbul.2019.06.027

85. Simaika, J. P., \& Samways, M. J. (2010). Biophilia as a Universal Ethic for Conserving Biodiversity. Conservation Biology, 24(3), 903-906. https://doi.org/10.1111/j.1523-1739.2010.01485.x

86. Siriaraya, P., \& Siang Ang, C. (2012). Age differences in the perception of social presence in the use of 3D virtual world for social interaction. Interacting with Computers, 24(4), 280-291. https://doi.org/10.1016/j.intcom.2012.03.003

87. Skarbez, R., Brooks, F. P., \& Whitton, M. C. (2018). Immersion and coherence in a stressful virtual environment. Proceedings of the 24th ACM Symposium on Virtual Reality Software and Technology, 1-11. https://doi.org/10.1145/3281505.3281530

88. Slater, M. (2009). Place illusion and plausibility can lead to realistic behaviour in immersive virtual environments. Philosophical Transactions of the Royal Society B: Biological Sciences, 364(1535), 3549-3557. https://doi.org/10.1098/rstb.2009.0138

89. Slater, M., \& Sanchez-Vives, M. V. (2016). Enhancing Our Lives with Immersive Virtual Reality. Frontiers in Robotics and Al, 3. https://doi.org/10.3389/frobt.2016.00074

90. Smith, K. D., Keating, J. P., \& Stotland, E. (1989). Altruism reconsidered: The effect of denying feedback on a victim's status to empathic witnesses. Journal of Personality and Social Psychology, 57(4), 641-650. https://doi.org/10.1037/0022-3514.57.4.641

91. Snapchat Advertising Costs. (2021). Wallaroo. https://wallaroomedia.com/snapchat-advertisingcosts/

92. Sommer, R. (2008). Semantic Profiles of Zoos and Their Animals. Anthrozoös, 21(3), 237-244. https://doi.org/10.2752/175303708X332044

93. Spangler, T. (2017). 'Game of Thrones' Snapchat Selfie Lens Reached 45 Million People. Variety. https://variety.com/2017/digital/news/game-of-thrones-snapchat-selfie-lens-1202504900/

94. Steptoe, W., Steed, A., \& Slater, M. (2013). Human Tails: Ownership and Control of Extended Humanoid Avatars. IEEE Transactions on Visualization and Computer Graphics, 19(4), 583-590. https://doi.org/10.1109/TVCG.2013.32

95. Steuer, J. (1992). Defining Virtual Reality: Dimensions Determining Telepresence. Journal of Communication. https://doi.org/10.1111/j.1460-2466.1992.tb00812.x

96. Stinson, J. (2017). Re-creating Wilderness 2.0: Or getting back to work in a virtual nature. Geoforum, 79, 174-187. https://doi.org/10.1016/j.geoforum.2016.09.002

97. Suso-Ribera, C., Fernández-Álvarez, J., García-Palacios, A., Hoffman, H. G., Bretón-López, J., Baños, R. M., Quero, S., \& Botella, C. (2019). Virtual Reality, Augmented Reality, and In Vivo Exposure Therapy: A Preliminary Comparison of Treatment Efficacy in Small Animal Phobia. Cyberpsychology, Behavior, and Social Networking, 22(1), 31-38. https://doi.org/10.1089/cyber.2017.0672

98. The Last Three Northern White Rhinos to be "Digitally Resurrected" in New York Using Augmented Reality. (2017, October 22). Indestry. https://www.indestry.com/news/the-last-three-northern-white- 
rhinos-to-be-digitally-resurrected-in-new-york-using-augmented-reality

99. Toet, A., Stokking, H., Klunder, T., M.C. van Berlo, Z., Smeets, B., \& Niamut, O. (2021). Augmented Reality-Based Remote Family Visits in Nursing Homes. ACM International Conference on Interactive Media Experiences, 258-263. https://doi.org/10.1145/3452918.3465502

100. Wang, I., Smith, J., \& Ruiz, J. (2019). Exploring Virtual Agents for Augmented Reality. Proceedings of the 2019 CHI Conference on Human Factors in Computing Systems, 1-12. https://doi.org/10.1145/3290605.3300511

101. Wilson, E. O. (1986). Biophilia. Harvard University Press.

102. Wrzesien, M., Botella, C., Bretón-López, J., del Río González, E., Burkhardt, J.-M., Alcañiz, M., \& PérezAra, M. Á. (2015). Treating small animal phobias using a projective-augmented reality system: A single-case study. Computers in Human Behavior, 49, 343-353. https://doi.org/10.1016/j.chb.2015.01.065

103. Xu, K., \& Liao, T. (2020). Explicating Cues: A Typology for Understanding Emerging Media Technologies. Journal of Computer-Mediated Communication, 25(1), 32-43. https://doi.org/10.1093/jcmc/zmz023

104. Yamada, M., \& Decety, J. (2009). Unconscious affective processing and empathy: An investigation of subliminal priming on the detection of painful facial expressions. Pain, 143(1), 71-75. https://doi.org/10.1016/j.pain.2009.01.028

105. Yin, J., Arfaei, N., MacNaughton, P., Catalano, P. J., Allen, J. G., \& Spengler, J. D. (2019). Effects of biophilic interventions in office on stress reaction and cognitive function: A randomized crossover study in virtual reality. Indoor Air, 29(6), 1028-1039. https://doi.org/10.1111/ina.12593

106. Yoo, S.-C., \& Drumwright, M. (2018). Nonprofit fundraising with virtual reality. Nonprofit Management and Leadership, 29(1), 11-27. https://doi.org/10.1002/nml.21315

107. Yoon, B., Kim, H., Lee, G. A., Billinghurst, M., \& Woo, W. (2019). The Effect of Avatar Appearance on Social Presence in an Augmented Reality Remote Collaboration. 2019 IEEE Conference on Virtual Reality and 3D User Interfaces (VR), 547-556. https://doi.org/10.1109/VR.2019.8797719

108. Zhang, X., \& Zhong, Z.-J. (2020). Extending media system dependency theory to informational media use and environmentalism: A cross-national study. Telematics and Informatics, 50, 101378. https://doi.org/10.1016/j.tele.2020.101378

109. Zimmer, A., Wang, N., Ibach, M. K., Fehlmann, B., Schicktanz, N. S., Bentz, D., Michael, T., Papassotiropoulos, A., \& de Quervain, D. J. F. (2021). Effectiveness of a smartphone-based, augmented reality exposure app to reduce fear of spiders in real-life: A randomized controlled trial. Journal of Anxiety Disorders, 82, 102442. https://doi.org/10.1016/j.janxdis.2021.102442

\section{Figures}




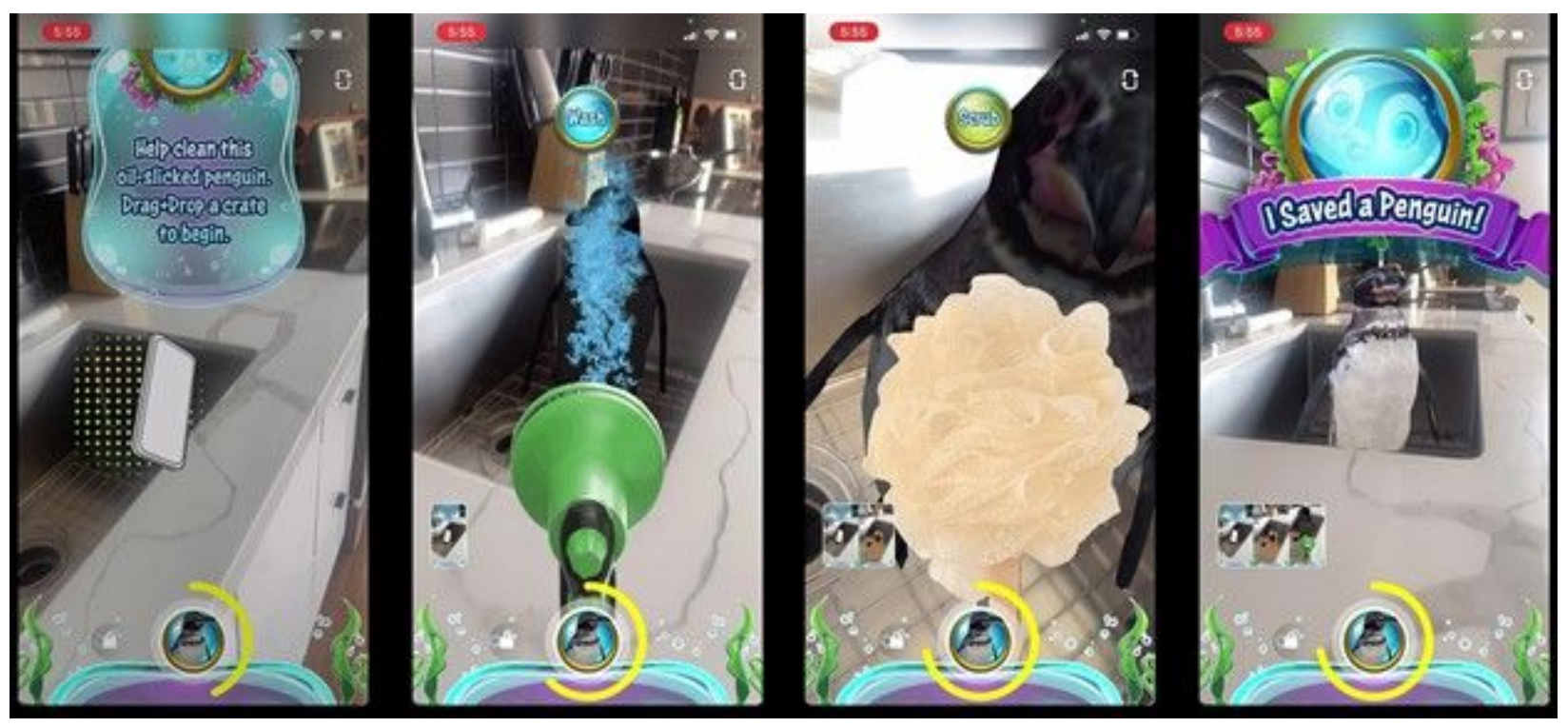

Figure 1

Screenshot of the Snapchat lens "Penguin Rescue!"

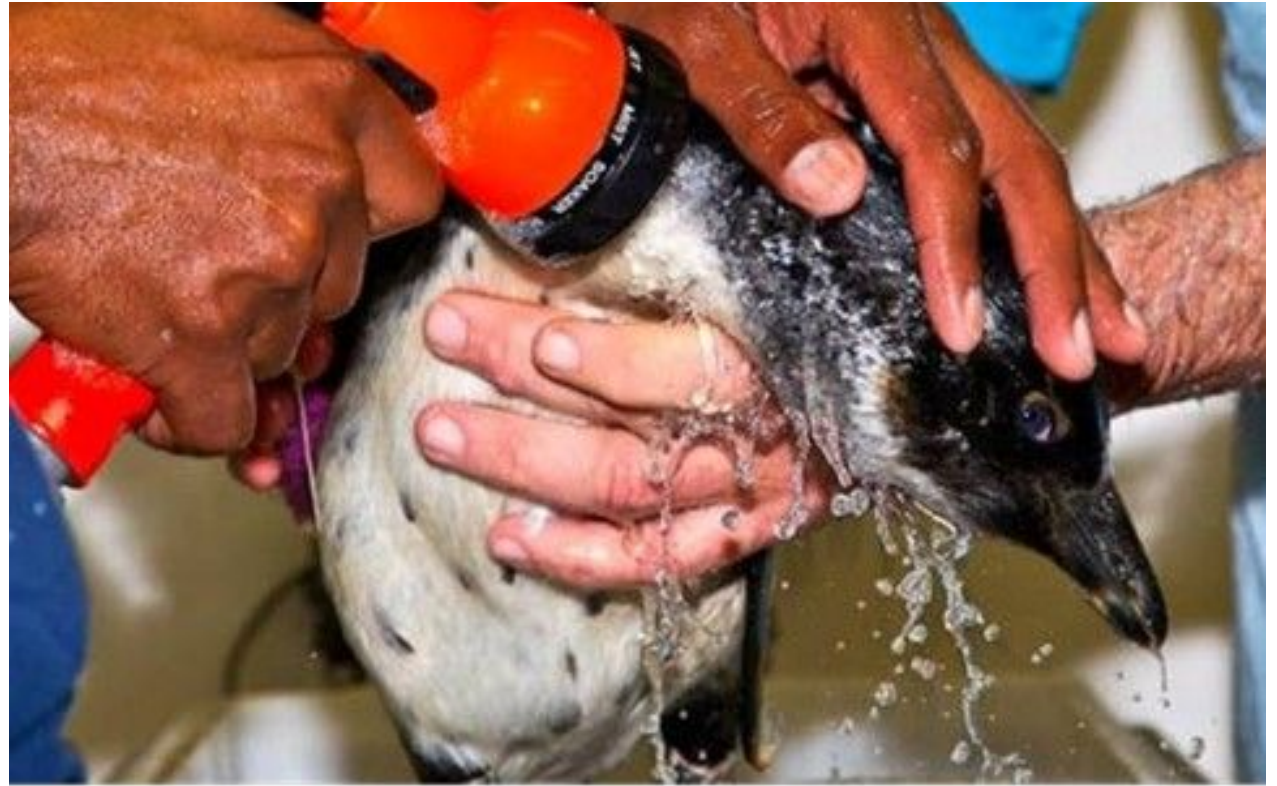

Figure 2

Example of how penguins are rehabilitated 
Changes in Dependent Variables After Using the Penguin Rescue! Lens

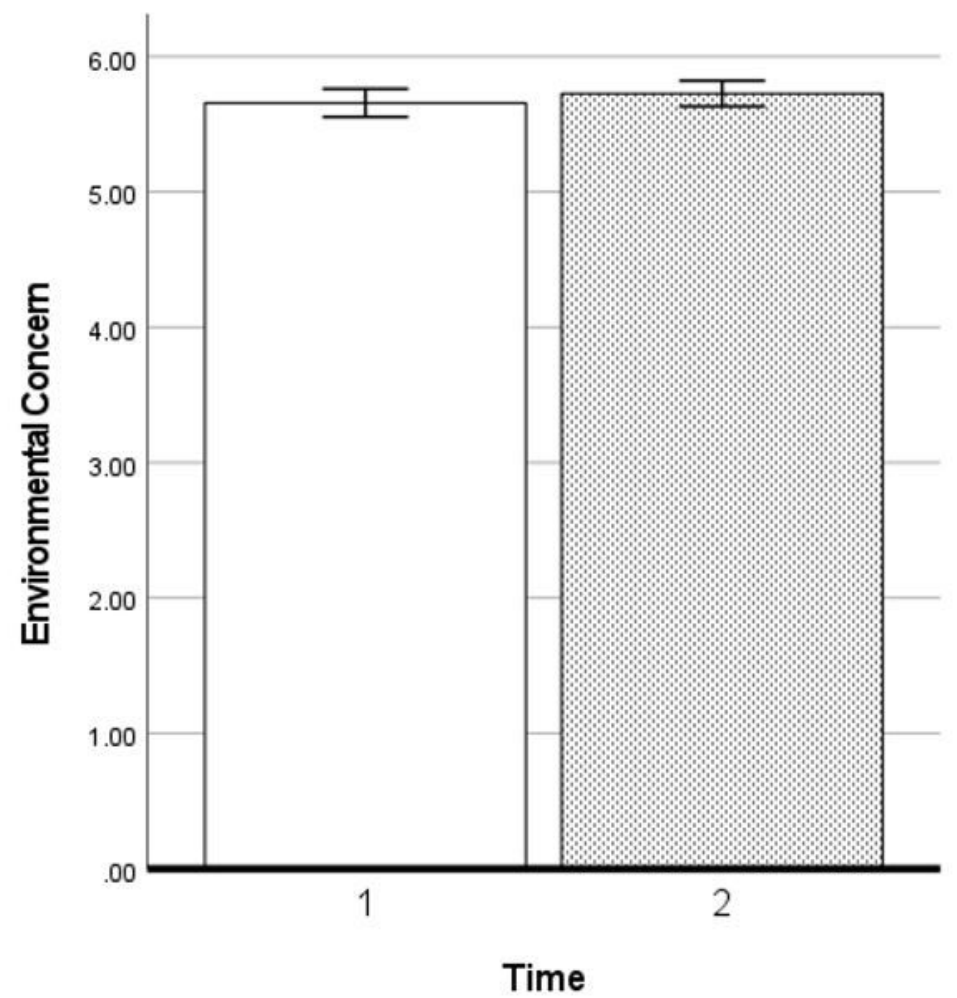

Error bars: +/- $1 \mathrm{SE}$

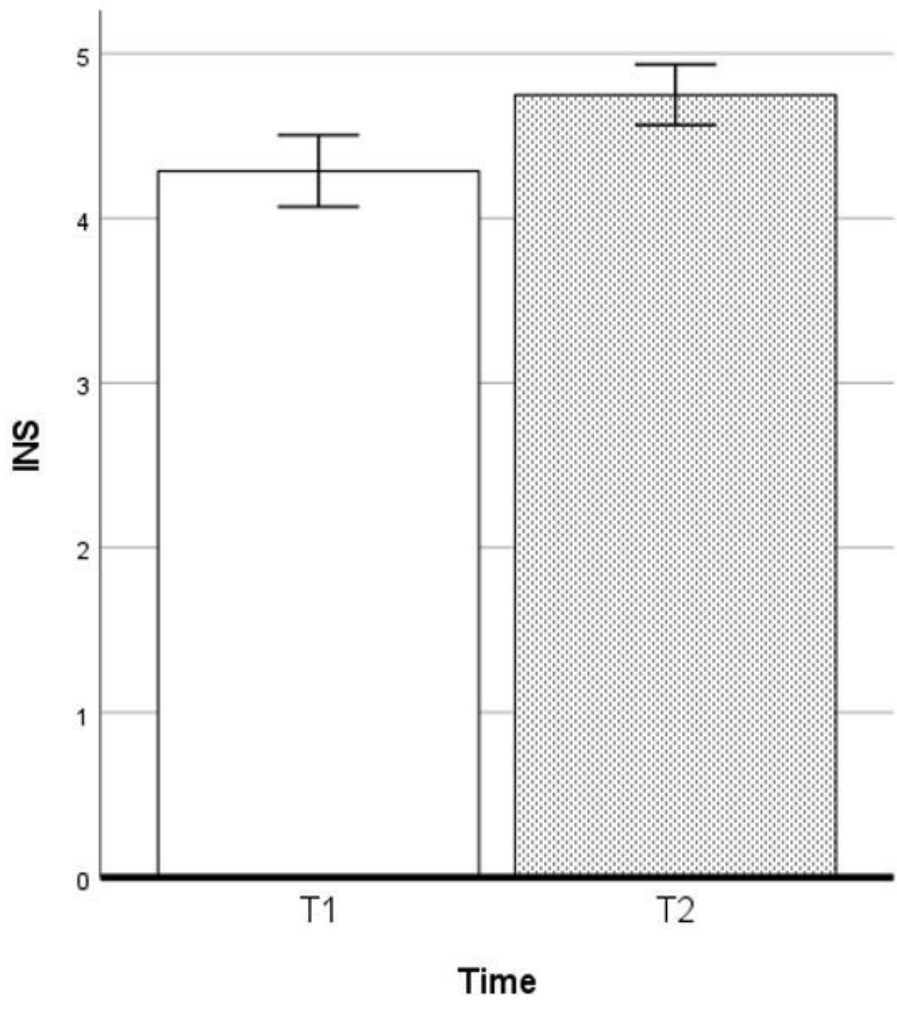

Error bars: +/- $1 \mathrm{SE}$

Figure 3

Changes in dependent variables after using the "Penguin Rescue!" lens 